\title{
PROBLEMATIZAÇÕES ÉTICAS: INQUIETUdES PARA A PESQUISA EM EDUCAÇÃO COM GÊNERO E SEXUALIDADE
}

\author{
LuIZ Felipe ZaGo \\ Universidade Luterana do Brasil (ULBRA), Canoas, Rio Grande do \\ Sul, Brasil \\ Bianca Salazar Guizzo \\ Universidade Luterana do Brasil (ULBRA), Canoas, Rio Grande do \\ Sul, Brasil \\ Luís Henrique Sacchi dos Santos \\ Universidade Federal do Rio Grande do Sul (UFRGS), Porto Alegre, \\ Rio Grande do Sul, Brasil
}

Resumo: Artigo teórico que trata da ética em pesquisa envolvendo seres humanos, com especial ênfase às pesquisas que tematizem gênero e sexualidade. A Resolução 466/2012, que regula a ética em pesquisa envolvendo seres humanos no Brasil, está baseada em um modelo válido para as ciências biomédicas, mas que não atende às problematizações das investigações das ciências sociais e humanas. Destacam-se as críticas a esse modelo, oriundas da Saúde Coletiva e da Antropologia. A seguir, procede-se à análise da situação da ética em pesquisas acerca de gênero e sexualidade situadas no campo feminista e dos estudos queer. Por fim, elegem-se as pesquisas com crianças, relevantes para o campo da Educação, como caso exemplar de investigações dificultadas pelo modelo de regulação vigente. Conclui-se que certos recortes teórico-metodológicos serão doravante impossíveis na hegemonia da ética biomédica.

Palavras-Chave: Ética em Pesquisa. Pesquisa em Educação. Gênero. Sexualidade. 
Observam-se hoje, no Brasil, intensos debates sobre a atuação dos Comitês de Ética em Pesquisa (CEP)' ${ }^{1}$. Os CEP, criados no período pós-guerra, são intensamente atuantes, sobretudo no campo da Medicina, área que produziu os mais importantes documentos de regulação de pesquisa envolvendo seres humanos - como a Declaração de Helsinque - na tentativa de salvaguardar a integridade e a dignidade de participantes de pesquisas clínicas (DINIZ, 2010; STARK, 2012). No nosso país, os CEP se baseiam na Resolução 466, de 2012, promulgada no âmbito do Conselho Nacional de Saúde (substituindo a Resolução 196/1996). A Resolução 466/2012 é o marco legal mais relevante da regulação ética em pesquisa envolvendo seres humanos no país e seu texto guia a consolidação do sistema formado por Comitês de Ética em Pesquisa supervisionado pela Comissão Nacional de Ética em Pesquisa (CONEP), conhecido como Sistema CEP-CONEP. Os referidos debates acerca da atuação dos CEP advêm, sobretudo, de áreas das Ciências Humanas, Sociais e Sociais Aplicadas, que contestam o modelo ético no qual se assentam os pressupostos teóricos e as exigências metodológicas de determinadas regulações demandadas pelos CEP às suas pesquisas. Dentre a heterogeneidade das críticas, podemos destacar como argumento comum a ineficácia do padrão biomédico de produção de conhecimento e de aferição da ética quando aplicado às pesquisas sociais e humanas.

Inserido no bojo dessas discussões, o presente artigo primeiramente elenca algumas críticas ao padrão de regulação ética em pesquisa do Sistema CEP/CONEP, formuladas por diferentes áreas do conhecimento. Nessa direção, destacam-se as críticas à Resolução 466/2012 oriundas dos campos da Saúde Coletiva e Antropologia. Escolhem-se essas duas áreas estrategicamente: a Saúde Coletiva pela urgência em inserir um viés qualitativo e social nas pesquisas hegemonicamente biologicistas da área da saúde; a Antropologia pela complexificação da posicionalidade do/a pesquisador/a-etnográfo/a inserido/a no campo e pelas críticas ao formato de Termo de Consentimento Livre e Esclarecido (TCLE) exigido de acordo com a Resolução.

Partindo das teorizações de Michel Foucault $(2009,2012 a)$ e de Judith Butler (1999, 2004, 2008, 2012) sobre sexo, gênero e sexualidade, em seguida são apresentadas considerações ético-metodológicas a respeito de pesquisas 
cujas temáticas se ocupem de corpo, gênero e sexualidade. Inspira-se nos aportes dos estudos feministas dos estudos queer pela crítica à neutralidade da produção de conhecimento e à normalização da matriz heterossexual. Por fim, elege-se como caso exemplar as pesquisas com gênero e sexualidade envolvendo crianças e com desenho teórico-metodológico qualitativo e participante para aludir àquilo que chamamos aqui de pesquisas doravante impossíveis, se nenhuma forma de resistência no campo da Educação procurar contestar a implementação acrítica da Resolução 466/2012 feita por alguns CEP.

Inobstante a relevância da problematização ética em pesquisa em sua indissociável articulação com a emergência dos Direitos Humanos no Ocidente (BEVILÁQUA, 2010; GUERRIERO; MINAYO, 2013), é preciso assinalar que são irredutíveis e não equivalentes certos princípios éticos nos procedimentos de pesquisas da área social e da área biomédica. $\mathrm{O}$ que tem ocorrido no funcionamento de muitos CEP é a aplicação de determinadas regras, válidas para as pesquisas biomédicas, mas que perdem seu sentido se aplicadas às pesquisas sociais e humanísticas.

O campo da Educação se vê particularmente interpelado a posicionar-se nesse complexo jogo de poder que tem caracterizado os debates sobre ética em pesquisa (DE LA FARE, MACHADO, CARVALHO, 2014; DE LA TAILLE, SOUZA; VIZIOLI, 2004), pois é tema central para a Educação pesquisar, investigar e analisar as relações através das quais educamos indivíduos e por meio das quais reconhecemos a alteridade como inseparável das relações de ensino-aprendizagem. Neste artigo, não se trata de negar a importância de haver a concordância dos sujeitos participantes em qualquer pesquisa, tampouco de defender uma posição que prescinda de grupos de pesquisadores/as que analisem propostas de pesquisa. Trata-se, em primeiro lugar, de circunscrever críticas ao modelo biomédico em funcionamento em muitos CEP e, em segundo, de assinalar alguns argumentos que possam subsidiar discussões sobre a ética em pesquisa envolvendo seres humanos nas pesquisas educacionais. 


\section{DOIS CAMPOS, CRÍTICAS COMUNS}

Dentre as críticas ao funcionamento de parte dos CEP no Brasil, aquelas oriundas da Saúde Coletiva destacam a hegemonia de um modelo biocêntrico de problematização ética (GUERRIERO; MINAYO, 2013). Tal modelo biocêntrico se assenta na crença de que a relação estabelecida entre pesquisador/a e participantes de pesquisa é a mesma tanto nas áreas clínicas e biomédicas quanto nas áreas sociais e humanas:

As pesquisas clínicas incluem: avaliação clínica e medição dos sinais vitais, como temperatura, pressão, batimentos cardíacos e outros, aos quais frequentemente se acrescenta a coleta de material biológico. Uma vez garantido que a pessoa possui as características necessárias para ser incluída na pesquisa, inicia-se o procedimento experimental. Muitas vezes o estudo se centra na utilização de um novo medicamento: o voluntário é orientado a utilizá-lo da maneira prevista na investigação e a comparecer aos retornos médicos para avaliação do efeito do seu uso no corpo (mais avaliações clínicas, medições dos sinais vitais e coleta de material biológico podem ser necessários). A proposta nesse caso é alcançar uma definição objetiva e isenta sobre a segurança e a eficácia (dependendo da fase da pesquisa) de determinado medicamento. (GUERRIERO; MINAYO, 2013, p. 769-770).

O modelo biocêntrico assenta-se na separação entre as posições de pesquisador/a (sujeito do conhecimento) e objeto do conhecimento (pesquisado/a), além de pressupor o controle total de todos os passos, etapas e possíveis efeitos das experimentações. Esses elementos são indispensáveis por se tratarem de pesquisas clínicas cujos procedimentos intervêm na materialidade orgânica dos corpos dos/as pesquisados/as. Portanto, esse é um modelo que pressupõe a exclusão da subjetividade do/a pesquisador/a, algo indispensável para a"produção de um conhecimento isento, imparcial e generalizável" (GUERRIERO; MINAYO, 2013, p. 770), além de exigir o controle das fases e previsibilidade dos efeitos das pesquisas.

Por outro lado, as vertentes da Saúde Coletiva, de modo geral, buscam compreender os processos saúde-doença como efeitos de relações sociais, econômicas, políticas e históricas, afastando-se dos determinismos biológicos nos quais se assentam no mais das vezes as ciências biomédicas. Ao investir em metodologias qualitativas, pesquisadores/as da Saúde Coletiva buscam 
afastar-se de explicações e pressuposições biologicistas na execução de suas pesquisas precisamente porque intentam sublinhar o caráter socialmente construído das diferentes concepções de saúde e de doença. Por essa razão, há um engajamento político intrínseco aos/às pesquisadores/as da Saúde Coletiva, que reivindicam que toda pesquisa qualitativa realizada neste campo precisa dispor de uma ética que lhe seja congruente. Assim, "o compromisso com as necessidades sociais de saúde parece orientar [...] as preocupações quanto aos processos de investigação e à possível contribuição dos resultados aos grupos sociais pesquisados" (CASTRO E SILVA; MENDES; NAKAMURA, 2012, p 40). O engajamento do/a pesquisador/a da Saúde Coletiva se dá geralmente pela sua preocupação em promover ou alterar certas políticas públicas de saúde, no sentido de melhorar as condições de execução dos serviços de saúde para os/as profissionais e também o acesso a esses serviços pela população em geral (OLIVEIRA et al., 2009).

Nesse contexto, a separação estrita da posição de pesquisador/a em relação àqueles/as pesquisados/as é borrada, e o domínio completo das etapas e efeitos da pesquisa fica difuso. No entanto, isso não significa que a problematização ética esteja suspensa ou ausente das pesquisas de caráter qualitativo desenvolvidas na Saúde Coletiva. A problematização ética em pesquisa está vinculada à análise da implicação do/a pesquisador/a, que se expressa no planejamento da pesquisa, na formulação das perguntas, no recorte do objeto, na escolha de determinados métodos de produção de dados, nas maneiras como são usados os conceitos e construídas as argumentações. Tudo depende de uma postura reflexiva e ética dos/as pesquisadores/ as, que está estreitamente ligada às diferentes maneiras pelas quais se dá seu engajamento, sua implicação com a pesquisa, com a temática, com o arcabouço teórico, com os/as participantes (GASTALDO; MACKEEVER, 2002; VÍCTORA, 2011).

$\mathrm{Na}$ Antropologia, são muitas as contestações dirigidas ao funcionamento atual de CEP no Brasil. A principal delas está precisamente atrelada às implicações do emprego da etnografia como metodologia de pesquisa cara a essa área do conhecimento. Nessa direção, Soraya Fleischer e Patrice Schuch (2010, p. 10) aludem que por meio da etnografia, "as categorias e práticas da 
experiência cotidiana ganham destaque a partir do confronto provocado por um estranhamento existencial que se renova durante o trabalho de campo". O/A etnógrafo/a envolve-se com as pessoas participantes da pesquisa, e tal envolvimento é condição sine qua non para o sucesso do trabalho de campo. Nesse sentido, o/a etnógrafo/a precisa construir relações de confiança com os/as participantes da pesquisa, relações que podem significar a construção de redes de convivência e de sociabilidade, que às vezes resultam na produção de esferas de intimidade com os/as pesquisados/as (HECKERT, 2010). Tal implicação coloca ao/à etnógrafo/a a questão da sua posicionalidade, isto é, a explicitação e análise acerca do lugar por ele/a ocupado em relação aos/ às participantes de pesquisa, mesmo que esse lugar seja momentâneo e constantemente modificado pelos imprevistos inerentes à etnografia (NASH, 2010). A posicionalidade do/a etnógrafo/a refere-se, portanto, à circunscrição dos modos como ele/a se relaciona com o campo de pesquisa e com os/as participantes enquanto categoria analítica necessária à pesquisa, na medida em que põe o/a pesquisador/a no patamar de sujeito da pesquisa, e não apenas como uma entidade apartada e isenta daquilo que busca conhecer.

Invariavelmente, o/a etnógrafo/a torna-se responsável pelas relações construídas durante o trabalho de campo com os/as participantes, pois são essas relações que permitem a realização da pesquisa, a entrada e a permanência no campo. Como referem Fleischer e Schuch (2010), a entrada e a permanência no campo são constituídas de renovados estranhamentos e negociações por parte do/a etnógrafo/a, o que pode levar a redefinições teóricas, metodológicas ou pode até mesmo levar à redefinição dos objetivos de pesquisa. Daí que uma importante crítica da Antropologia ao modelo biocêntrico de aferição de ética em pesquisa repousa na inflexibilidade do conceito de consentimento e na rigidez do formato dos TCLE, tal como exige a Resolução 466/2012 (OLIVEIRA, 2010). O TCLE existe como documento juridicamente válido no qual todas as informações sobre o desenrolar da pesquisa precisam ser explicitadas, e em linguagem adequada, para que os/as participantes possam "livre e esclarecidamente" decidir se querem ou não participar (RAYMUNDO, 2013). Porém, no caso da etnografia, se os imprevistos e surpresas são inerentes (e às vezes bem-vindos) à tarefa de 
pesquisar, torna-se impossível controlar todos os passos da investigação antes da entrada em campo.

Se a pesquisa e seu desenho teórico-metodológico mudam ao longo do trabalho de campo etnográfico, como é possível que um termo assinado no início da pesquisa seja ainda válido até seu fim? Alguns autores sugerem que o consentimento livre e esclarecido é antes um processo do que um momento (RIBEIRO, 2014), e que o consentimento precisa ser contínuo e não único (MUELLER; INSTONE, 2008). Na prática, isso significa que o/a pesquisador/a tem a obrigação de informar e re-informar, de negociar e re-negociar com os/as participantes a todo o instante sobre o desenrolar da pesquisa. Na Antropologia, muitas vezes a manifestação do consentimento em participar de uma pesquisa se dá através da aceitação tácita ou implícita por parte dos/as participantes, aceitação que é intrínseca à construção da relação de confiança necessária para a entrada em campo. Face ao modelo biocêntrico de regulação ética em pesquisa, operado por muitos CEP, essa forma de consentimento não é válida. Pois, nesse modelo,

o consentimento explícito deve ser demonstrado e formalizado através da assinatura de um termo pelos participantes da pesquisa. Isso tem sido abordado como algo bastante problemático para os antropólogos, especialmente nos casos em que o consentimento "livre e esclarecido" (o caráter desse esclarecimento é sempre polêmico) pode colocar em risco a situação ou a condição de vida dos participantes, como na pesquisa sobre tráfico de drogas e diversas outras atividades consideradas ilegais. Mas tal procedimento também pode ser problemático nos casos em que inibe ou dirige excessivamente o discurso dos sujeitos da pesquisa, mesmo quando o procedimento não envolve riscos objetivos. (OLIVEIRA, 2010, p. 29).

Isto é: um único formato juridicamente reconhecido para o consentimento, expresso no TCLE, não condiz com as múltiplas dimensões com as quais a pesquisa etnográfica precisa lidar. Não existe uma única forma de consentir "livre e esclarecidamente", tampouco o TCLE garante a proteção dos/as participantes de pesquisa - muitas vezes, inclusive, a assinatura do termo constrange os/as participantes e às vezes incrementa sua vulnerabilidade, como no caso da pesquisa etnográfica entre usuários de drogas ilícitas (MCRAE; VIDAL, 2006). Esse é um importante ponto de tensão: a discussão 
sobre o consentimento dos/as participantes está intimamente ligada aos objetivos da pesquisa, à temática estudada, ao desenho teórico-metodológico e à posicionalidade do/a pesquisador/a, que às vezes expressa seu engajamento para com os grupos pesquisados - engajamento este que, no modelo biocêntrico, eventualmente é interpretado como interesse particular do/a pesquisador/a e, por isso, é considerado antiético.

Todas as complexificações indicam que um único modelo ético não dá conta de avaliar as implicações da realização das pesquisas sociais. É preciso, assim, recusar uma única regulação ética e propor múltiplas problematizações éticas, de acordo com as particularidades de cada investigação social e humana. Ciméa Bevilaqua (2010), ao transpor a dualidade observador/a-observado/a do campo da Física para a Antropologia, sugere que todo universo de pesquisa nas Ciências Sociais e Humanas contém, em si próprio, multiplicidades de dimensões que coexistem e que se sobrepõem. "Uma das consequências dessa multiplicidade é o esforço que se impõe ao pesquisador para identificar e compreender as relações entre os diversos planos" (BEVILAQUA, 2010, p. 81). Para a autora, os diversos planos que compõem um dado universo de pesquisa também implicam na multiplicidade de problemáticas éticas surgidas no campo e que se colocam para os/as pesquisadores/as.

Podemos sugerir que o uni-verso de pesquisa torna-se um multi-verso de pesquisa: ele não é único, mas múltiplo; essa multiplicidade é efeito de uma série de atravessamentos que constitui a pesquisa (o seu recorte, o seu objeto, os seus pressupostos, o seu arcabouço teórico, o conjunto de métodos utilizados, atravessamentos do/a pesquisador/a que a conduz, do/a orientador/a que a coordena ou orienta, da instituição de ensino e pesquisa que a financia). Aquele/a que faz pesquisa tem entre suas tarefas compreender esses multi-versos de pesquisa e, antes disso, compreender também que sua própria existência estabelece limites e potências para o pesquisar. Cada multi-verso de pesquisa tem suas próprias demandas éticas, exigindo diferentes formas de consentimento por parte dos/as pesquisados/as, demandando múltiplas e complexas conexões entre o lugar social e político do/a pesquisador/a em sua relação com aqueles/as que pesquisa. 
PESQUISANDO COM CORPO, GÊNERO E SEXUALIDADE NO MULTI-VERSO DE PESQUISA

Michel Foucault (2009a) sublinha que é preciso ater-se a quem fala, como fala, desde que lugar fala, em que circunstância fala, para quem fala, e quais efeitos essa fala produz. As regras que condicionam o discurso constituem a verdade daquilo que é dito e também legitimam o lugar daquele/a que diz (FOUCAULT, 2012a, 2009a; 2009b). Mas o lugar daquele/a que diz não é personalizado, isto é, o discurso não é produção de uma consciência autônoma e original de um sujeito fundante; pelo contrário, é o discurso que constitui aquele/a que fala, nas condições nas quais fala; aquele/a que fala é antes falado/a pelo discurso, posicionado/a como falante por um determinado conjunto de regras. Se um alguém não é falado/a, ou seja, se não lhe é engendrado lugar no discurso, esse alguém não se torna inteligível. Eis a luta constituinte da ordem do discurso, na perspectiva foucaultiana: preencher o lugar vazio de quem diz e ter voz enquanto um sujeito falante (falante porque falado), de modo que aquilo que é dito legitime o lugar de quem diz como um alguém, como um alguém viável, como um alguém inteligível, como um alguém que existe no mundo e para o mundo.

Por sua vez, Judith Butler $(2004,2008,2012)$ sugere que os lugares de sexo-gênero são, eles próprios, lugares de inteligibilidade da vida. Somente quando nossos corpos atravessam um limiar da matriz heterossexual é que ganhamos possibilidade de ter voz, de ter corpos que falam, corpos políticos e culturalmente inteligíveis. O limiar da matriz heterossexual seria o processo através do qual nossos corpos são observados, distinguidos, classificados, separados e posicionados em lugares de sexo-gênero produzidos em relação à heterossexualidade, tida como sexualidade normal e desejável (BUTLER, 2012; LOURO, 2004). O limiar da matriz heterossexual seria um princípio ontológico para aferição da humanidade. Um corpo resistente, indiscernível e inclassificável em relação à norma heterossexual constitui um dos domínios da abjeção e não goza do status de sujeito (PRINS; MEIJER, 2002). Se um corpo se acomodar "adequadamente" ao seu lugar de sexo-gênero previamente engendrado, a partir daí poderá ter voz e poderá constituir-se como um corpo que fala: "a categoria do sexo constitui e regula aquilo que será uma existência humana 
inteligível e reconhecível, o que será e o que não será um/a cidadão/ã capaz de direitos e de fala" (BUTLER, 2008, p. 101). Trata-se de uma imbricação de sexo e gênero (por isso sexo-gênero), no qual o sexo (macho "ou" fêmea) parece presidir as construções de gênero (masculinidades e feminilidades), tornando-as mutuamente excludentes: "é-se macho ou fêmea, nunca os dois ao mesmo tempo, e nunca nenhum dos dois" (BUTLER, 2008, p. 101). Na ordem do discurso, a matriz heterossexual policia os lugares de enunciação.

Essas são algumas proposições pertinentes a partir das quais podemos abordar as complexidades da pesquisa com corpo, gênero e sexualidade: nós, pesquisadores/as de gênero e de sexualidade, falamos? Somos cultural e politicamente inteligíveis? Temos corpos que falam, que pesquisam? Se sim, é porque de uma maneira ou de outra atravessamos o limiar da matriz heterossexual sugerido por Butler. Acomodamo-nos de modos mais ou menos confortáveis aos lugares previamente engendrados para nós (e por nós) nas cristalizações das masculinidades, das feminilidades, das identidades sexuais; praticamos mais ou menos "adequadamente" os atos performativos de gênero que se sedimentam nos corpos e que se repetem no tempo (BUTLER, 1999, 2008).

Somos, portanto, agentes nas construções de sexo-gênero e de sexualidade em uma dada cultura, em um dado período histórico: nós, pesquisadores/as, não deixamos nossos sexos, gêneros e sexualidades do lado de fora do campo de pesquisa. Não fazemos pesquisas "sobre" gênero e sexualidade, mas fazemos pesquisas "com" gênero e sexualidade. Dizemos "sim" ao gênero que nos foi designado: é como se, ao sermos chamados de João ou de Maria, e ao respondermos a esse chamamento, ativássemos performativamente uma longa cadeia de direitos, restrições, possibilidades e limites inerentes e previamente agregados aos lugares de gênero designados para cada um desses nomes. E é precisamente essa longa cadeia de relações sociais e políticas que buscamos pesquisar, analisar e eventualmente desconstruir. Enquanto pesquisadores/as generificados/as e sexualizados/as, estamos implicados/ as no funcionamento do dispositivo de sexualidade (FOUCAULT, 2012b), que produz nossos lugares de sexo como nossas essências, que articula nossos desejos às nossas identidades sexuais. 
Porém, por mais implicados/as e engajados/as nas análises das relações por meio das quais tal matriz heterossexual e tal dispositivo de sexualidade funcionam, nós podemos estar também engajados/as politicamente na sua desconstrução e na crítica aos seus processos de normalização. É essa perspectiva política que orienta algumas pesquisas inspiradas em vertentes feministas e, sobretudo, nos estudos queer (LOURO, 2004; MISKOLCI, 2009). Wendy Chapkis (2010), na esteira das problematizações dos feminismos estadunidenses - lembremos do slogan "o pessoal é político" -, sugere que a implicação do/a pesquisador/a social com seu objeto e com sua metodologia de pesquisa exprime um engajamento eminentemente político, mas não só isso: a reboque da implicação do/a pesquisador/a com o tema (e com os/as participantes) de pesquisa, veem também a complexidade e as contradições inseparáveis de tal implicação.

Para Chapkis, a complexidade e as contradições do não distanciamento entre sujeito e objeto de pesquisa não são infrutíferas ou poluidoras: "O engajamento - enraizado tanto na biografia quanto num conjunto de valores políticos - é o que impulsiona minha carreira acadêmica; é o que me permite escrever"2 (CHAPKIS, 2010, p. 484, tradução nossa). Para a autora, pesquisar assumindo o "viés" e a parcialidade inerentes a qualquer pesquisador/a social é algo inevitável e, sobretudo, produtivo. $O$ engajamento do/a pesquisador/a, nessa perspectiva, é uma atitude que recusa o silêncio da pesquisa, entendido como a neutralidade e a imparcialidade do/a pesquisador/a, e é precisamente aquilo que dá condições para os/ as pesquisadores/as terem voz no ato de fazer pesquisa. Nesse sentido, o engajamento posiciona os/as pesquisadores/as como sujeitos falantes no interior do multi-verso de pesquisa.

Se o emprego radical da proposição feminista "o pessoal é político" mantém-se em íntima relação com o engajamento do/a pesquisador/a na pesquisa e com os/as participantes, aquelas investigações da área social que analisam os modos como se dão as construções das experiências de sexualidade desde uma perspectiva construcionista, feminista ou queer, demonstram a recusa (e a impossibilidade) da imparcialidade e da separação estrita entre pesquisador/a-pesquisados/as. Nesse sentido, o engajamento 
do/a pesquisador/a com a temática e com os/as participantes não pode ser simplesmente reduzido à categoria de "interesse particular", algo que comprometeria a conduta da pesquisa e o conhecimento produzido por meio dela. Pelo contrário, o engajamento, a implicação do/a pesquisador/a social são precisamente condições para a construção de uma ética de pesquisa singular, uma ética que é inerentemente metodológica, isto é, intrínseca ao desenvolvimento da pesquisa e à conduta do/a pesquisador/a social (DETAMORE, 2010). É o que propõe Marcos Ferreira (2013, p. 188):

A centralidade da reflexão ética marca as ciências sociais desde os seus primórdios e determina os moldes da sua profissionalização crescente, impondo a obrigação aos seus profissionais, não apenas de regularem as técnicas da sua pesquisa, mas de refletirem sobre os propósitos e objetivos da sua atividade. Nesse sentido, um risco que afeta diretamente todas as ciências sociais é o de que tanto as abordagens conceituais quanto as estratégias de investigação empírica do universo social se tornem meros instrumentos de validação argumentativa das ordens sociopolíticas.

É importante assinalar o perigo que certo modelo de aferição da ética em pesquisa venha a transformar a produção de conhecimento em "mero instrumento de validação argumentativa" de ordens e normas vigentes. Por exemplo, algumas pesquisas inspiradas nos estudos queer estão em tensão com a demanda pelo anonimato dos/as participantes, tal como demanda o modelo ético biocêntrico. Porque, ao manter o anonimato de participantes de pesquisa assumidamente não heterossexuais com o argumento (legítimo) de protegê-los/as de eventuais práticas de violência discriminatória, também se está reiterando a matriz heterossexual que silencia e invisibiliza os indivíduos que contestam uma sexualidade compulsória, tida como normal (JACKMAN, 2010). Se, por um lado, se está preservando a integridade de participantes de pesquisa por meio do anonimato, por outro também se reforça uma norma que as pesquisas politicamente engajadas da área social, sobre gênero e sexualidade, buscam criticar.

Se é verdade que o anonimato é demandado para proteger os/ as participantes, também é verificável que o anonimato pode significar a reificação de certas relações de estigmatização. Nessa díade, apostamos no engajamento político do/a pesquisador/a, que pode se dar pela afirmação de 
sua posição de sujeito, pela explicitação da sua posicionalidade em relação aos/às participantes, e não pela invisibilização ou ocultação dessa posição ou relação. Em consonância com Chapkis (2010), Denílson Lopes (2002) sugere que a "saída do armário" dos/as pesquisadores/as no próprio processo de fazer pesquisa pode delimitar certo modo de engajar-se na afirmação de novas formas de existência no mundo. Aqui, a "saída do armário" não diz respeito apenas a assumir uma determinada sexualidade; diz respeito a se assumir como um sujeito que ocupa um determinado lugar como autor, um determinado lugar na ordem do discurso; diz respeito a entender seu lugar como pesquisador/a em relação ao multi-verso de pesquisa. "Sair do armário", nesse contexto, pode significar a elucidação dos elementos constitutivos da subjetividade do/a próprio/a pesquisador/a que serão inseparáveis dos modos pelos quais ele ou ela se colocarão ao longo do processo de pesquisa e, ao fim e ao cabo, os modos pelos quais ele/a produzirá conhecimento (GASTALDO, 2012).

\section{FINALIZAÇÕES: AS PESQUISAS DORAVANTE IMPOSSÍVEIS}

Discutindo sobre o imperativo inflexível de aplicação do TCLE, de acordo com os moldes de regulação ética biocêntrica, Mónica De la Fare, Frederico Machado e Isabel Carvalho (2014, p. 272) alertam:"alguns recortes de pesquisa seriam inviabilizados caso fosse exigida a autorização dos pais, tais como: [...] crianças e adolescentes homossexuais, transexuais e travestis, dentre outros temas polêmicos". Sonia Kramer (2002) já lançou profícuas perguntas sobre as ambíguas significações do anonimato de crianças participantes de pesquisa, bem como questionou quem são os sujeitos que têm a autoridade de consentir no lugar das crianças. A autora indaga (KRAMER, 2002, p. 42):

os nomes verdadeiros das crianças - observadas ou entrevistadas - devem ou não ser explicitados na apresentação da pesquisa? No caso de serem usadas e produzidas imagens das crianças (fotografias, vídeos ou filmes), a autorização dada pelos adultos, em geral seus pais, é suficiente, do ponto de vista ético, para a sua divulgação? Que implicações ou impacto social têm os resultados de trabalhos científicos? Ou, dizendo de outra forma, é possível contribuir e devolver os achados, evitando que as crianças ou jovens sofram 
com as repercussões desse retorno no interior das instituições educacionais que freqüentam e que foram estudadas na pesquisa?

Não procuraremos responder a essas instigantes perguntas; porém, utilizar-nos-emos delas para problematizar as pesquisas envolvendo crianças que tematizem sobre gênero e sexualidade no campo da Educação - pesquisas politicamente estratégicas e relevantes, haja vista, por exemplo, a intensa polêmica acerca da inclusão de materiais pedagógicos visando o combate à homofobia nos espaços escolares, uma das estratégias do já esquecido projeto do Ministério da Educação "Escola Sem Homofobia". Nesse sentido, o caso das pesquisas qualitativas e participantes com crianças a respeito das construções de gênero e de sexualidade, e que lançam mão de arcabouços teórico-metodológicos de inspiração feminista e queer, são um caso exemplar de um conjunto de investigações das áreas humanas e sociais que estão em vias de extinção se o modelo de regulação ética biocentrado permanecer incontestado.

As crianças, ao longo do século XX, passaram a ganhar visibilidade como tema relevante de pesquisa, especialmente no campo da Educação. Foi a partir de meados da primeira década do século XXI que as crianças começaram a ser colocadas como protagonistas dos processos de investigação. Começa-se a observar todo um movimento que defende não só a realização de pesquisas "sobre" crianças, mas "com" crianças. Tal movimento vincula-se ao fato de cada vez mais pesquisadores/as interessarem-se por procurar analisar as maneiras como as crianças estão imersas nas culturas das quais participam, como "ressignificam e constroem sentidos particulares sobre os espaços que frequentam, sobre os produtos que consomem e sobre sua participação ativa 'como agente e co-construtora de seu desenvolvimento"' (MÜLLER; CARVALHO, 2009, p. 24). Nesse tipo de investigação as crianças são compreendidas como sujeitos atuantes no espaço cultural e social, não como passivas diante das práticas em que são envolvidas.

Autoras como Jucirema Quinteiro (2002), Leena Alanen (2001), Rita Ribes Pereira (2002) e Sonia Kramer $(2008,2002)$ atribuem especial importância às metodologias que privilegiam as falas e as atitudes de crianças, uma vez que são sujeitos que têm suas próprias ideias provenientes das 
experiências vividas em seus cotidianos. As referidas autoras salientam que muitas pesquisas realizadas em torno da temática da infância problematizam alguns artefatos culturais que são produzidos para essa população; porém, partem da visão de pesquisadores/as adultos/as, o que acarreta a não escuta das opiniões das crianças. Daí a importância de se conferir um maior espaço aos seus comportamentos, às suas atitudes e às suas falas.

Aqueles/as pesquisadores/as que desenvolvem investigações acerca das construções de gênero e de sexualidade junto a crianças no campo da Educação, entendendo que existem práticas pedagógicas que atuam na produção das masculinidades, feminilidades e sexualidades dentro e fora do âmbito escolar (LOURO, 2007), poderão enfrentar muitas dificuldades para desenvolver pesquisas de cunho etnográfico, por exemplo. Em primeiro lugar, pela ambiguidade entre uma posição teórico-política que visa legitimar a posição de sujeito "criança" na sua autonomia discursiva, dando atenção às suas falas e práticas, e à exigência do consentimento livre e informado da criança em participar da pesquisa - que, nesse caso, seria um "assentimento" dos pais, familiares ou responsáveis legais, que autorizariam no lugar da criança sua participação. Mesmo assim, o "assentimento" pela criança continuaria sendo um "consentimento" dos pais ou responsáveis. Em segundo lugar, como sugeriu Kramer (2002), o anonimato da criança como participante de pesquisa nem sempre contribui para a qualificação política das análises na produção de conhecimentos que melhorem e intervenham na condição de crianças em estado de vulnerabilidade (como o caso de crianças em suspensão de liberdade), bem como não garante sua proteção a eventuais danos subjetivos, afetivos ou emocionais.

Ainda, em terceiro lugar, a adoção de perspectivas teóricas como as dos feminismos e dos estudos queer, que promovem a politização da produção de subjetividades e a crítica às normalizações da matriz heterossexual, aliadas a desenhos metodológicos nos quais existe a construção de relações entre pesquisador/a e participantes (como a etnografia, as entrevistas, as observações participantes de modo geral) partem de princípios conceituais e políticos que se chocam contra o modelo biocêntrico de aferição da ética em pesquisa. Isso acontece por se tratarem de pesquisas que recusam a 
neutralidade do/a pesquisador/a em relação ao tema e em relação aos/às participantes de pesquisa, bem como desconfiam que a imparcialidade do/a pesquisador/a e a exigência de anonimato dos/as participantes está a serviço da consolidação da norma heterossexual - precisamente o que se busca criticar. Nessa direção, as demandas pela separação estrita entre pesquisador/a e participantes de pesquisa, e pelo distanciamento crítico sobre o tema pesquisado, característicos de certo modelo biocêntrico de ética em pesquisa, estão em tensão com proposições como a do engajamento político enquanto estratégia de recorte de objeto, de desenho metodológico, de execução de pesquisa e de publicação das análises.

O campo da Educação poderia se servir e transformar as críticas aqui elencadas, oriundas dos campos da Saúde Coletiva e da Antropologia e também de outras áreas, na construção de posições que interroguem o modo de funcionamento hegemônico de muitos CEP, baseado em diretrizes contidas na Resolução 466/2012, que desconsidera as singularidades das pesquisas sociais e humanísticas. Duas ressalvas a esse respeito: a primeira é que não se defende um "vale-tudo" a-ético. Pesquisadores/as, sejam eles/as das ciências humanas e sociais ou da área biomédica, não podem fazer o que quiserem, com quem quiserem e do modo como quiserem. Precisamente por isso acredita-se, sim, que é necessário haver problematizações éticas (como aponta o título deste artigo) em fóruns especialmente constituídos para tanto. Argumenta-se que ética é uma dimensão inerente às investigações sociais e que há múltiplas éticas possíveis nessas pesquisas, sobretudo naquelas que se valem de metodologias qualitativas, participantes, que necessitam da construção de relações de confiança entre pesquisadores/as e participantes. Por isso, discorda-se de uma regulação ética cujo processo tem-se dado com base em um modelo estranho às Ciências Humanas e Sociais, e que funciona unicamente para aferir se uma pesquisa tem ou não tem ética. Discorda-se também que a função de um CEP seja de policiamento moral ou utilitarista dos procedimentos de pesquisa. Apostamos que esses espaços se ocupem em problematizar eticamente as implicações e os engajamentos existentes no desenvolvimento de muitas pesquisas sociais, levando a cabo discussões que considerem as especificidades dos 
campos do conhecimento, seus variados arcabouços teóricos, seus desenhos metodológicos e sua relevância no interior das mais variadas realidades sociais e políticas.

A segunda ressalva diz respeito à evitação da adoção de uma posição homogeneamente contrária ao modelo biocêntrico que orienta muitos CEP. Pois não há consenso entre as múltiplas vertentes das Ciências Humanas e Sociais sobre como se pode fazer um enfrentamento unificado e coerente à colonização biocêntrica da discussão sobre ética em pesquisa envolvendo seres humanos no Brasil. Se as vertentes mais radicais, como certas teorizações feministas e, sem dúvida, os estudos queer, parecem extrapolar alguns limites que muitos/as pesquisadores/as sociais acreditam que devam permanecer inalterados, também é possível inspirar-se em seu gesto teórico e político, que busca colocar sob escrutínio analítico todo tipo de cristalização normativa que sedimenta relações de poder e reifica ordens sociais de subordinação. Trata-se não da busca de uma posição unívoca que seja contrária à regulação ética biocêntrica, mas da construção de uma pluralidade de posições, de uma multiplicidade de posturas que interroguem, com argumentos consistentes, a ética biocêntrica.

Nessa direção, salienta-se que a Educação, enquanto campo no qual se entrecruzam e se sobrepõem variadas perspectivas teóricas e múltiplas orientações metodológicas, pode construir suas próprias (e heterogêneas) éticas em pesquisa em diálogo com as demais áreas das Ciências Sociais e Humanas, éticas que sejam debatidas e problematizadas em fóruns que "considerem a diversidade de concepções científicas, de destinatários dos conhecimentos produzidos e de interesses envolvidos" (DE LA FARE; MACHADO; CARVALHO, 2014, p. 274). E que se impeça, assim, que alguns dispositivos de produção de conhecimento, de análise social, se tornem inviáveis e impossíveis graças a modelos éticos inflexíveis e burocráticos. 


\section{ETHICAL PROBLEMATIZATIONS: DISQUIETUDES FOR EDUCATIONAL RESEARCH ON GENDER AND SEXUALITY}

ABSTRACT: A theoretical article that discusses ethics in research involving human subjects, and in particular, researches in the areas of gender and sexuality. The Resolution 466/2012, regulating ethics in research on human subjects in Brazil, is based on a model that is appropriate for biomedical sciences but not equally applicable to research in social and human sciences. Salience is given here to critiques of the biomedical model that have been elaborated from Public Health and Anthropological perspectives. This is followed by an analysis of ethics in gender and sexuality research that is linked to feminism and queer studies. Finally, given its relevance to the field of Education, research with children is examined as an exemplary case of the type of work that falters when current models of ethical regulation are applied. In conclusion, certain theoretical and methodological themes become unapproachable when subjected to the hegemony of biomedical ethics.

KEYwORDS: Research ethics. Research in Education. Gender. Sexuality.

\section{PROBLEMATIZACIONES ÉTICAS: INQUIETUDES PARA LA INVESTIGACIÓN EN EL CAMPO EDUCATIVO CON GÉNERO Y SEXUALIDAD}

RESUMEN: Este artículo teórico aborda el tema de la ética en investigaciones con seres humanos, con especial énfasis en aquellas que discuten género y sexualidad. La Resolución 466/2012, que regula la ética en investigaciones con seres humanos en Brasil, se basa en un modelo válido para las ciencias biomédicas, pero que no atiende el problema de las investigaciones en ciencias sociales y humanas. Se destacan las críticas a ese modelo originarias de la Salud Pública y de la Antropología. A seguir, se procede el análisis de la situación de la ética en investigaciones sobre género y sexualidad ubicadas en los campos feministas y de estudios queer. Finalmente, se elijen las investigaciones con niños, relevantes en el campo de la Educación, como caso ejemplar de investigaciones dificultadas por el modelo de regulación vigente. Se concluye que ciertos recortes teórico-metodológicos pueden hacerse imposibles en la hegemonía de la ética biomédica.

PalABRAS-CLAVE: ética de investigación. Investigación en educación. Género. Sexualidad. 


\section{NOTAS}

1) Os Comitês congregam pesquisadores/as especializados/as, aptos/as a analisar propostas de atividades e acompanhar o desenvolvimento de pesquisas envolvendo seres humanos em todas as áreas do conhecimento.

2) “[...] Engagement-rooted both in biography and in a set of political values-is what pushes my scholarship forward; it is what enables me to write."

\section{REFERÊNCIAS}

ALANEN, L. Estudos Feministas/Estudos da Infância: paralelos, ligações e perspectivas. In: CASTRO, L. R. (Org.). Crianças e jovens na construção da cultura. Rio de Janeiro: Nau Editora, 2001. p. 69-92.

BEVILAQUA, C. Ética e planos de regulamentação em pesquisa: princípios gerais, procedimentos contextuais. In: FLEISCHER, S.; SCHUCH, P. (Org.). Ética e regulamentação na pesquisa antropológica. Brasília: Letras Livres/Editora Universidade de Brasília, 2010. p. 71-90.

BUTLER, J. Gender trouble. 2. ed. New York: Routledge, 1999.

. Undoing gender. New York: Routledge, 2004.

Inversões sexuais. In: PASSOS, I. C. F. (Org). Poder, normalização e violência Incursões foucaultianas na atualidade. Belo Horizonte: Autêntica, 2008. p. 90-108.

BUTLER, J. Cuerpos que importan - Los límites discursivos del sexo. 2. ed. Buenos Aires, Paidós. 2012.

CASTRO E SILVA, C. R.; MENDES, R.; NAKAMURA, E. A Dimensão da Ética na Pesquisa em Saúde com Ênfase na Abordagem Qualitativa. Saúde e Sociedade, São Paulo, v.21, n.1, p. 32-41, 2012.

CHAPKIS, W. Productive Tensions: Ethnographic Engagement, Complexity, and Contradiction. Journal of Contemporary Ethnography. v. 39, n. 5, p. 483-497, 2010.

DE LA FARE, M.; MACHADO, F. V.; CARVALHO, I. C. M. Breve revisão sobre regulação da ética em pesquisa: subsídios para pensar a pesquisa em educação no Brasil. Práxis Educativa, Ponta Grossa, v. 9, n. 1, p. 247-283, jan./jun. 2014.

DE LA TAILLE, Y. L. S.; DE SOUZA, L.; VIZIOLLI, L. Ética e educação: uma revisão da literatura educacional de 1990 a 2003. Educação e Pesquisa, São Paulo, v.30, n.1, p. 91-108, jan./abr. 2004.

DETAMORE, M. Queer(y)ing the Ethics of Research Methods: Toward a Politics of Intimacy in Researcher/Researched Relations. In: BROWNE, K.; NASH, C. J. (Org.). Queer Methods and Queer Methodologies - Intersecting Queer Theories and Social Science Research. Burlington: Ashgate, 2010. p. 167-182. 
DINIZ, D. Pesquisa social e os Comitês de Ética no Brasil. In: FLEISCHER, S.; SCHUCH, P. (Org.). Ética e regulamentação na pesquisa antropológica. Brasília: Letras Livres/Editora Universidade de Brasília, 2010. p. 183-192.

FERREIRA, M. F. A ética da investigação em ciências sociais. Revista Brasileira de Ciência Política, Brasília, n. 11, p. 169-191, maio/ago. 2013.

FLEISCHER, S.; SCHUCH, P. Apresentação - Antropologia, ética e regulação. In: (Org.). Ética e regulamentação na pesquisa antropológica. Brasília: Letras Livres/Editora Universidade de Brasília, 2010. p. 9-21.

FOUCAULT, M. A ordem do discurso. 18. ed. São Paulo: Edições Loyola, 2009a.

O que é um autor? In: MOTTA, M. B. (Org.). Ditos \& Escritos III - Estética: Literatura, Pintura, Música e Cinema. 2. ed. Rio de Janeiro: Forense Universitária. 2009b. p. 264-298.

A arqueologia do saber. 8. ed. São Paulo: Forense Universitária. 2012a.

A História da sexualidade I - A vontade de saber.. Rio de Janeiro, Graal. $2012 \mathrm{~b}$.

FRANCISCO, D. J.; SANTANA, L. Introdução - Problematizações éticas em Pesquisa. In: (Org.). Problematizações éticas. Maceió: EDUFAL, 2014. p. 17-26.

GASTALDO, D.; MCKEEVER, P. Investigación cualitativa, intrínsecamente ética? In: MERCADO F. J.; GASTALDO, D.; CALDERÓN, C. (Org.). Investigación cualitativa en salud en Iberoamérica - Métodos, análisis y ética. Universidad de Guadalajara, Universidad Autónoma de San Luis Potosí, Universidad Autónoma de Nuevo Léon, 2002. p. 475-480.

GASTALDO, D. Pesquisador/a descontruído/a e influente? Desafios da articulação teoria-metodologia nos estudos pós-críticos. In: MEYER, D. E.; PARAÍSO, M. A. (Org.). Metodologias de Pesquisas Pós-Críticas em Educação. Belo Horizonte: MAZZA Edições, 2012. p. 9-14.

GUERRIERO, I. C. Z.; MINAYO, M. C. S. O desafio de revisar aspectos éticos das pesquisas em ciências sociais e humanas: a necessidade de diretrizes específicas. Physis Revista de Saúde Coletiva, Rio de Janeiro, vol. 23, n. 3, p. 763-782, 2013.

HECKERT, J. Intimacy with strangers/intimacy with self, Queer experience of social research. In: BROWNE, K.; NASH, C. J. (Org.). Queer Methods and Queer Methodologies - Intersecting Queer Theories and Social Science Research. Burlington: Ashgate, 2010. p 41-54.

JACKMAN, M. C. The Trouble with Fieldwork - Queering Methodologies. In: BROWNE, K.; NASH, C.J. (Org.). Queer Methods and Queer Methodologies - Intersecting Queer Theories and Social Science Research. Burlington: Ashgate, 2010. p. 113-128.

KRAMER, S. Autoria e Autorização: questões éticas na pesquisa com crianças. Cadernos de Pesquisa, São Paulo, n. 116, p. 41-59, julho 2002. 
KRAMER, S. Crianças e adultos em diferentes contextos - Desafios de um percurso de pesquisa sobre infância, cultura e formação. In: SARMENTO, M.; GOUVEA, M. C. (Org.). Estudos da Infância: Educação e Práticas Sociais. Petrópolis, RJ: Vozes, 2008, p.163-189.

LOPES, D. O homem que amava rapazes - e outros ensaios. Rio de Janeiro, Aeroplano, 2002.

LOURO, G. L. Um corpo estranho - ensaios sobre teoria queer. Belo Horizonte, Autêntica, 2004.

Pedagogias da sexualidade. In: LOURO, G. L. (Org.). O corpo educado - pedagogias da sexualidade. Belo Horizonte: Autêntica, 2007. p. 7-34.

MAcRAE, E.; VIDAL, S. A Resolução 196/96 e a imposição do modelo biomédico na pesquisa social, Dilemas éticos e metodológicos do antropólogo pesquisando o uso de substâncias psicoativas. Revista de Antropologia v. 49, n. 2. p. 645-66, 2006.

MISKOLCI, R. A Teoria Queer e a Sociologia: o desafio de uma analítica da normalização. Sociologias, ano 11, n. 21, p. 150-182, jan./jun. 2009.

MUELLER, M.; INSTONE, S. Para além do consentimento informado: consentimento contínuo em pesquisa com seres humanos. Ciência \& Saúde Coletiva, n. 13, v. 2. p. 381-389, 2008.

MÜLLER, F.; CARVALHO, A. M. Editorial. Psicologia USP, São Paulo, n. 20, p. 9-11, 2009.

NASH, C. J. Queer Conversations: Old-time Lesbians, Transmen and the Politics of Queer Research. In: BROWNE, K.; NASH, C.J. (Org). Queer Methods and Queer Methodologies - Intersecting Queer Theories and Social Science Research. Burlington: Ashgate, 2010. p. 129-142.

OLIVEIRA, G.N. et al. Novas possibilidades de militância no campo da saúde: a afirmação de desvios no encontro entre trabalhadores, gestores e usuários do SUS. Interface - Comunic., Saude, Educ., v.13, supl.1, p. 523-529, 2009.

OLIVEIRA, L. R. C. A antropologia e seus compromissos ou responsabilidades éticas. In: FLEISCHER, S.; SCHUCH, P. In: FLEISCHER, S.; SCHUCH, P. (Org.). Ética e regulamentação na pesquisa antropológica. Brasília: Letras Livres/Editora Universidade de Brasília, 2010. p. 25-38.

PEREIRA, R. R. Infância, televisão e publicidade: uma metodologia de pesquisa em construção. Cadernos de Pesquisa, São Paulo, n. 116, p. 81-105, julho/2002.

PRINS, B.; MEIJER, I. C. Como os corpos se tornam matéria - entrevista com Judith Butler. Revista de Estudos Feministas, Florianópolis, v. 10, n. 1, p. 155-167, 2002.

QUINTEIRO, J. Infância e Educação no Brasil: um campo de estudos em construção. In: FARIA, A. L.; DEMARTINI, Z.; PRADO, P. (Org.). Por uma cultura da infância: metodo- 
logia de pesquisa com crianças. Campinas, São Paulo: Autores Associados, 2002. p. 19-47.

RAYMUNDO, M. M. Consentimento informado: desde sus Orígenes hasta las nuevas perspectivas bajo el marco intercultural. Colonia del Carmen: Fontamara, 2013.

RIBEIRO, J. S. Questões éticas da pesquisa em Antropologia. In: FRANCISCO, D. SANTANA, L. (Org.). Problematizações éticas. Maceió: EDUFAL, 2014. p. 69-102.

STARK, L. Behind closed doors - IRBs and the making of ethical research. Chicago: University of Chicago Press, 2012.

VíCTORA, C. G. Uma Ciência Replicante: a ausência de uma discussão sobre o método, a ética e o discurso. Saúde e Sociedade, São Paulo, v.20, n.1, p.104-112, 2011.

LuIz Felipe ZaGo: Doutor em Educação pela Universidade Federal do Rio Grande do Sul (UFRGS) na Linha de Pesquisa em Educação, Sexualidade e Relações de Gênero. Professor Permanente do Programa de Pós-Graduação em Educação da Universidade Luterana do Brasil. Atualmente é pesquisador vinculado ao Núcleo de Estudos Currículo, Cultura e Sociedade (NECCSO) e pesquisador participante do Projeto Medicalização da Escola \& Produção Contemporânea dos Corpos, ambos na Faculdade de Educação da UFRGS. Suas áreas de interesse são relações de gênero, corpo, sexualidade, saúde, Direitos Humanos, produção de subjetividades, mídia e ética.

E-mail: professorluizfelipezaso@smail.com

Bianca Salazar Guizzo: Doutora em Educação pela Universidade Federal do Rio Grande do Sul (UFRGS). Atualmente é pesquisadora e professora adjunta do Programa de Pós-Graduação em Educação da Universidade Luterana do Brasil (PPGEDU/ULBRA), onde está inserida na linha de pesquisa Infância, Juventude e Espaços Educativos. É integrante do Grupo de Estudos de Educação e Relações de Gênero (GEERGE), vinculado à UFRGS, desde 2001. Além disso, desenvolve e participa de projetos de pesquisa vinculados à ULBRA e à UFRGS cujas temáticas envolvem políticas públicas e legislação da educação básica, infância, gênero, sexualidade e Estudos Culturais. E-mail: bguizzo_1@hotmail.com 
Luís Henrique Sacchi dos Santos: Doutor em Educação pela Universidade Federal do Rio Grande do Sul (UFRGS). Professor Associado no Departamento de Ensino e Currículo da Faculdade de Educação da UFRGS. Tem experiência na área de Educação, atuando principalmente nos seguintes temas: estudos culturais em educação, estudos de gênero $e$ sexualidade, estudos de corpo, corpo e saúde, cultura somática, educação em saúde (promoção da saúde), medicalização, biossociabilidade, biologia cidadã e biopedagogias.

E-mail: luishss2009@gmail.com 
